\title{
INVESTIGATING NON-ACADEMIC CORRELATES OF GOAL COMMITMENT FOR ACADEMIC ACHIEVEMENT AT HIGHER EDUCATION LEVEL
}

\author{
Meral Şeker, \& Nilgün Tatar \\ Faculty of Education, Alanya Alaaddin Keykubat University (Turkey)
}

\begin{abstract}
Academic performance is dependent not only on personal traits but also on non-academic factors such as personal, socio-cultural, political, or economic (e.g., Poropat, 2009; Stoet \& Geary, 2015). These factors, referred as psycho-social contextual influences (Richardson, Abraham, \& Bond, 2012), are significant determinants in academic performance at particularly higher education level. In this respect, the present study attempts to explore university students' goal commitment to academic achievement by focusing on social, economic, and political factors playing role in their determination to engage in academic studies. The data, gathered through semi-structured interviews and focus-group discussions with 116 university students, was analyzed qualitatively following open coding procedure. The results indicated that economic and political influences are among frequently reported factors, which could be significant determinants in their level of academic engagement. The findings suggest that such psycho-social contextual influences need further consideration in the context of defining and assessing achievement at higher education level in addition to instructional, academic, or personal factors. Therefore, any attempt towards understanding and enhancing learners' academic performance should also involve consideration of psycho-social contextual determinants.
\end{abstract}

Keywords: Higher education, non-academic factors, goal commitment, academic achievement, psycho-social context.

\section{Introduction}

Academic success of the learners is mostly associated with academic traits either related to the learner; such as intelligence, cognitive and metacognitive skills, individual learning strategies, and so on, or to the teaching context; such as teaching practices, materials, the teacher, assessment procedures, etc. However, research on the exploration of the significant predictors of academic achievement of learners has often demonstrated incomplete or inconsistent findings, which may indicate that these variables are insufficient in explaining or predicting learners' academic potential (Poropat, 2009; Zwick, 2004). Although it is as important to investigate the combination of these traits in order to optimize the conditions of learning situations for an increased learner engagement, it is equally crucial to consider non-academic factors such as socio-cultural, economic, or political conditions under which a specific learning situation exists.

A large body of research has identified various strong predictors of academic achievement that are not directly related to the capacities of the learner or to the learning task itself (e.g., Adenike \& Oyesoji, 2010; Cheng \& Kaplowitz, 2018; Li, et al., 2018). Studies focusing on such psycho-social contextual influences on academic success have reported various variables that are significant determinants in academic engagement and in the degree of learner resilience. For example, Cheng and Kaplowitz (2018) investigated close social relations impacting academic success and concluded that family economic status and cultural capital were significant determinants in academic achievement. The findings reported in other studies conducted in different contexts report similar findings emphasizing the stronger effect of family income or socio-economic status on learners' academic success than the learning resources provided (Acemoglu \& Pischke, 2001; Li, et al., 2018; Richardson, Abraham, \& Bond, 2012).

Similarly, studies focusing on the impacts of socio-political context have indicated strong non-academic predictors such as racial or ethnic discrimination, terrorism, or wars in academic engagement and success (Adenike \& Oyesoji, 2010; Conger \& Atwell, 2012; English, Lambert \& Ialongo, 2016). Moosmann, Roosa, and Knight (2014) investigated the effect of 'immigration paradox' 
in the context of Mexican immigrants in the U.S. on the academic performance of the learners. The findings indicated that perceived discrimination was a strong determinant correlating negatively with academic achievement.

In this respect, the present paper aims to report the preliminary findings of the study being conducted to investigate psycho-social contextual influences on the goal commitment to academic achievement of university students in Turkey. Due to the space limits, the present study presents the results related to economic and political factors playing role in learners' determination to attain higher achievement.

\section{Method}

Qualitative in nature, the study was conducted following grounded theory, which is defined by Strauss and Corbin, (1998) as "a qualitative research design in which the inquirer generates a general explanation of a process, action, or interaction shaped by the views of a large number of participants". As the present study aims to reach a general pattern of interacting factors affecting learners' academic achievement, Charmaz's (2006) constructive approach for grounded research design was followed in order to obtain and interpret the opinions, experiences, feelings, and assumptions of the participating students. For the analysis of the data, open coding procedure was applied. The open coding procedure was conducted in three stages: (a) analysis of the data for forming the main categories; (b) segmentation of the data for forming subcategories within each category; and finally, (c) identifying the themes emerging under each subcategory.

\subsection{Data collection procedure}

The data for the study was gathered through semi-structured interviews and focus-group discussions with university students studying in different departments. Upon receiving consents of the students to participate, they were interviewed by the researcher. All interviews took place at the campus each lasting around 10 minutes. The semi-structured interviews included six questions directed towards three main aspects: the student's demographic information (e.g., age, gender, family background); their perception of self academic achievement level; and the factors playing role in their academic achievement. The interviews were recorded and transcribed by the researcher. Subsequent to the analysis of the data from the interviews, the participants were grouped according to the type of the influencing factors they stated as personal, social state of the community, economic state of the community, and the political state of the community. However, due to the space limit, only the findings related to the economic and political state of the community will be discussed in this paper.

In the next step, focus group discussions were held with each group. As a form of qualitative research method, focus group discussion differs from one-to-one interviews with the participants in a way that allows participants to interact with each other on a given issue or issues instead of just answering the researcher's questions (Wong, 2008). As the aim was exploring the participants' views on the factors influencing their academic engagement based on their shared context, group interaction would yield more in-depth opinions and experiences voiced by the participants themselves without the interference of the researcher as an outsider. As some students were in more than one group, four group discussions were organized on separate days. For each group discussion, there were between 18 and 24 students joining. All discussions, which lasted between 72 minutes to 96 minutes, were recorded and transcribed verbatim.

\subsection{Participants}

The study was conducted with the participation of 116 students at a state university on a voluntary basis. Their demographic information is displayed in Table 1.

Table 1. Demographic Information on the Participant Students.

\begin{tabular}{|ccccccccc|}
\hline \multicolumn{4}{c}{ Gender } & \multicolumn{3}{c|}{ Age } & Department \\
& $\mathrm{F}$ & $\mathrm{M}$ & $19-20$ & $21-25$ & $26-30$ & Education & Engineering & Tourism \\
$\%$ & 51.7 & 48.2 & 50.8 & 32.7 & 16.3 & 53.4 & 26.7 & 19.8 \\
\hline
\end{tabular}

Of the participants, 60 were female and 56 male students aged between 19 and 30. They were studying in the faculties of education, engineering or tourism at a state university. When asked for their family socio-economic status, none of the participants stated that they were from high-income families; but mostly from middle-income families $(80.1 \%)$. 
Table 2. Family Background of the Participant Students.

\begin{tabular}{|lcccccccc|}
\hline \multicolumn{3}{c}{ Economic Income } & \multicolumn{5}{c|}{ Number of Siblings } \\
& Low & Middle & High & No sibling & 1 & $2-3$ & $4-5$ & $6+$ \\
$\%$ & 19.8 & 80.1 & - & 23.2 & 23.2 & 43.1 & 14.6 & 12.9 \\
\hline
\end{tabular}

The findings indicate that $23.2 \%$ of the participants had no siblings and the majority $(43.1 \%)$ had 2 or 3 siblings. The number of the siblings varied between 1 and 6 and more.

\section{Findings}

The analysis of the data gathered from the interviews shows that the majority of the participants consider themselves as academically successful (78.8\%). When asked the level of their academic success, most of them identified themselves as high achievers $(39.6 \%)$ followed by average $(28.4 \%)$ and poor $(12.9 \%)$ academic levels.

Table 3. The Participants' Perceptions on their Academic Success.

\begin{tabular}{|llllllll|}
\hline & Academically Successful & \multicolumn{5}{c|}{ Level of Academic Success } \\
& Yes & No & Very High & High & Average & Poor & Very Poor \\
Total & 77.8 & 22.1 & 1.7 & 39.6 & 28.4 & 12.9 & 5.1 \\
\hline
\end{tabular}

When the participants were asked whether non-academic factors affected their academic involvement, the majority of the responds were affirmative $(87.9 \%)$ and the rest of them stated that no factors outside academic life impacted their involvement (12\%). Table 4 presents the non-academic factors reported by the participants.

Table 4. Source of Non-Academic Factors Affecting Goal Commitment.

\begin{tabular}{|lcccc|}
\hline \multicolumn{1}{|c}{ Factors } & Education & Engineering & Tourism & Total \\
& $\%$ & $\%$ & $\%$ & $\%$ \\
Personal Factors & 67.7 & 45.1 & 56.5 & 59.4 \\
Immediate Social Environment & 58.0 & 38.7 & 60.8 & 55.1 \\
Social State of the Community & 32.2 & 41.9 & 69.5 & 42.2 \\
Economic State of the Community & 35.5 & 58.0 & 82.6 & 54.3 \\
Political State of the Community & 30.6 & 35.4 & 52.1 & 32.7 \\
\hline
\end{tabular}

Accordingly, personal factors were the most influential in their success $(59.4 \%)$, followed by immediate social environment $(55.1 \%)$, economic state of the community $(54.3 \%)$, and social state of the community $(42.2 \%)$. Despite having considerably high rate of responses, factors related to political state of the community were the least frequently stated ones $(32.7 \%)$.

Formed based on their choice of factors, the participants were invited to join the group discussions. During the focus group discussions held with the participant students, their views and experiences of the factors they had stated influencing their academic success were explored. The themes emerging as a result of these discussions are presented in Table 5 and Table 6.

Table 5. Responses for the Economic State of the Community.

\begin{tabular}{|lc|}
\hline Factors with Negative Influence & $\mathbf{\%}$ \\
Insufficient scholarships and funding opportunities for university students & 88.2 \\
Expensive accommodation for students (dorm/flat/guesthouse, etc.) & 84.4 \\
Inequality in economic income and financial opportunities & 79.6 \\
Expensive educational materials (books, laptops, resource books, etc.) & 77.4 \\
High unemployment rate for university graduates & 77.2 \\
Having lots of families with minimum wage income & 71.4 \\
Insufficient support to academic / university studies in the country & 56.6 \\
Not enough part-time job opportunities for university students & 54.6 \\
\hline
\end{tabular}


When participants were asked to indicate the factors related to the economic state of their country and state how they impacted their academic success, no respond was recorded indicating positive effect. According to the participants, the economic state of the country was not supportive of their academic studies. The most frequent response was directed to insufficient funding for university students. The students also mentioned about the inequality in economic income as an influencing factor. As one student put it: "If you are from a rich family, you study at private schools, get the best education and become even richer than your family. But, if you are from a poor family, you are destined to stay poor all your life". Being from low-income families was yet another negatively influencing factor: "My family has difficulty in supporting my studies here. I have two other siblings at secondary school as well. They think when I graduate I will be able to support them and they will be comfortable. But I am not sure if I will ever find a job". For others, university graduation did not guarantee a job and therefore, studying at a university was unnecessary: "School is waste of time and money in my country. Education is not necessary to be rich. You need to know the right people or to have a rich family. That's it"

As the second influencing factor focused on in the study, the impact of the perceived political state of the country was explored in the focus group discussions. The emerging themes are presented in Table 6.

Table 6. Responses for the Political State of the Community.

\begin{tabular}{|llll|}
\hline Factors with Negative Influence & $\%$ & Factors with Positive Influence & \% \\
Having too many political conflicts & 86.2 & Feeling that my country needs me & 46.4 \\
Having Syrian refugees & 84.6 & Feeling responsible to defend my country & 44.6 \\
Feeling worried about my country's future & 80.4 & Having a strong government motivates me & 28.6 \\
Having unfair appointment system & 78.6 & & \\
Having poor legislative system & 78.4 & \\
Feeling under political pressure/oppressive attitude & 74.8 & \\
Having instable political state & 72.4 & \\
Having wrong political and educational system & 70.4 & \\
Having bad reputation in the world & 64.4 & \\
The fear of terrorism & 58.6 & & \\
Ethnic and political discrimination & 46.4 & & \\
\hline
\end{tabular}

The analysis revealed three positively influencing themes: feeling needed by the country (46.4\%), feeling responsible for the country (44.6\%), and having a strong government in the country $(28.6 \%)$. As one student explained: "I use all the problems happening in my country and the surrounding countries as forces to motivate me to study more. If I am strong and educated, I can defend my country".

However, the majority of the responses were under negatively influencing states. The highest frequencies were having political conflicts, or refugees in the country as well as being worried about the country. An excerpt by a participating student exemplifies the psychological state of some students: "You cannot expect people to study and to be successful when there is a war in your country". Also, having unfair appointment system and poor legislative system seemed to demotivate some students as voiced by the following excerpts: "Bribes, inequalities, privileges, injustice, ignorance and so on. Why do I need to study more?". "Since whatever the people that govern us say has to happen in my country, I don't think my academic achievements will make a difference".

Some of the participants, on the other hand, felt hopeless about the future: "Thinking that I am silenced in my country affects my studies and makes me hate everything. For example, giving so much power to the police and the security forces in my country and not being able to have a say on anything demotivates me. Then I think studying more won't change anything". "Every day I hear people appointed to different jobs and earning huge amounts. There are too many preferential treatments in life. Why study, I don't know". "Not having a fair political system destroys my hope for the future in every way".

\section{Conclusion}

This paper introduces the preliminary findings of a large scale study that aims to explore non-academic correlates of university students' academic achievement. As a country going through substantial political, social, and economic changes, Turkey presents a challenging context for educators and students. In addition to theoretical and instructional dimensions involved in teaching-learning situations, learners' wider context including the psycho-social contextual influences need to be considered in order to be able to support and guide learners more effectively. As the findings indicate, the majority of 
the university students reported that non-academic factors impacted their goal commitment to academic involvement and achievement negatively. Thus, attempts towards understanding, planning and enhancing learners' academic involvement and performance need to involve consideration of psycho-social contextual determinants, particularly at higher education level.

\section{References}

Acemoglu, D., \& Pischke, J. S. (2001). Changes in the wage structure, family income, and children's education. European Economic Review, 45(4-6), 890-904.

Adenike, A. O., \& Oyesoji, A. A. (2010). The relationship among predictors of child, family, school, society and the government and academic achievement of senior secondary school students in Ibadan, Nigeria. Procedia-Social and Behavioral Sciences, 5, 842-849.

Charmaz, K. (2006). Constructing grounded theory: A practical guide through qualitative analysis. Sage Publications.

Cheng, S. T. \& Kaplowitz, S. A. (2016). Family economic status, cultural capital, and academic achievement: The case of Taiwan. International Journal of Educational Development, 49, 271-278.

Conger, D., \& Atwell, M. S. (2012). Immigrant gateway communities: Does immigrant student achievement vary by location? In Garcia Coll, C., \& Marks, A.K. (Eds.). The immigrant paradox in children and adolescents: Is becoming American a developmental risk? (pp. 233-252). Washington, DC: American Psychological Association.

English, D., Lambert, S. F., \& Ialongo, N. S. (2016). Adding to the education debt: Depressive symptoms mediate the association between racial discrimination and academic performance in African Americans. Journal of School Psychology, 57, 29-40.

Moosmann, D. A., Roosa, M. W., \& Knight, G. P. (2014). Generational patterns in Mexican Americans' academic performance in an unwelcoming political context. Journal of Applied Developmental Psychology, 35(2), 102-110.

Li, J., Han, X., Wang, W., Sun, G., \& Cheng, Z. (2018). How social support influences university students' academic achievement and emotional exhaustion: The mediating role of self-esteem. Learning and Individual Differences, 61, 120-126.

Poropat, A. E. (2009). A meta-analysis of the five-factor model of personality and academic performance. Psychological Bulletin, 135(2), 322.

Richardson, M., Abraham, C., \& Bond, R. (2012). Psychological correlates of university students' academic performance: A systematic review and meta-analysis. Psychological Bulletin, 138(2), 353-387.

Strauss, A., \& Corbin, J. (1998). Basics of qualitative research techniques. Thousand Oaks, CA: Sage publications.

Stoet, G., \& Geary, D. C. (2015). Sex differences in academic achievement are not related to political, economic, or social equality. Intelligence, 48, 137-151.

Wong, L. P. (2008). Focus group discussion: a tool for health and medical research. Singapore Med J, 49(3), 256-60.

Zwick, R. (2004). Is the SAT a "wealth test?" The link between educational achievement and socioeconomic status. In R. Zwick (Ed.). Rethinking the SAT (pp. 203-216). New York, NY: Routledge Falmer. 